\title{
Proteinograma sérico e do líquido peritoneal de equinos hígidos e daqueles submetidos à obstrução intestinal experimental
}

\author{
Serum and peritoneal protein profile of healthy horses and horses subjected \\ to experimental intestinal obstruction
}

\author{
Andressa Francisca Silva Nogueira ${ }^{\mathrm{I}^{*}}$ Paula Alessandra Di Filippo $^{\mathrm{II}}$ Letícia Abrahão Anai $^{\mathrm{I}}$ \\ Gener Tadeu Pereira' ${ }^{\mathrm{II}}$ Aureo Evangelista SantanaI
}

RESUMO

Avaliou-se a resposta de fase aguda através da concentração das proteinas de fase aguda (PFA) no soro sanguíneo e no líquido peritoneal de vinte e um equinos, hígidos e submetidos à obstrução intestinal experimental, distribuídos em quatro grupos: obstrução de duodeno - GD $(n=6)$, íleo - $G I(n=6)$, cólon dorsal esquerdo - GM $(n=6)$ e controle instrumentado - GC $(n=3)$. Foram colhidas amostras de sangue e liquido peritoneal e, após centrifugação e fracionamento, as proteinas de fase aguda foram separadas por eletroforese em SDS-PAGE. Identificaramse as proteinas $\operatorname{Ig} A$, ceruloplasmina, transferrina, albumina, $\operatorname{Ig} G$, haptoglobina, $\alpha_{1}$-glicoproteína ácida e P24, no soro e no líquido peritoneal. Houve aumento nas concentrações sérica e peritoneal de todas as PFA, sendo mais evidente no líquido peritoneal e nos animais obstruidos. O fracionamento eletroforético das PFA no líquido peritoneal é mais eficaz no diagnóstico de processos inflamatórios abdominais, quando comparado ao sérico.

Palavras-chave: sangue, líquido peritoneal, equinos, cólica, proteinas de fase aguda.

\section{ABSTRACT}

It was evaluated the acute phase response over the concentration of acute phase proteins (APP) in serum and in peritoneal fluid of twenty-one healthy equines submitted to experimental intestinal obstruction distributed in groups: duodenal obstruction (GD), ileum obstruction (GI), left-dorsal colon (GM), and instrumentalized control (GC). Blood and peritoneal liquid samples were collected, after centrifugation and fractioning and the acute phase proteins were separated by electrophoresis in $S D S-P A G E$. The acute phase proteins (APP) identified were IgA, ceruloplasmin, transferrin, albumin, IgG, haptoglobin, $\alpha_{1}$-acid glycoprotein and P24, in the serum and liquid peritoneal. There was anincrease in the serum and peritoneal proteins concentrations evidencing a higher response of the APP from the peritoneal fluid and of the obstructed groups. The electrophoretic separation of the proteins included in the peritoneal liquid is more effective when compared to the serum concentration in the diagnosis of abdominal inflammatory processes.

Key words: blood, peritoneal fluid, horses, colic, acute phase proteins.

\section{INTRODUÇÃO}

A síndrome cólica é uma das principais causas de urgência cirúrgica em equinos. O desencadeamento do quadro de cólica não depende, na maioria das vezes, de um único fator de risco (LARANJEIRA \& ALMEIDA, 2008). Tais fatores, isolados ou combinados, internos ou externos, podem interagir de várias formas, dando início a alterações fisiológicas (TRAUB-DARGATZ, 2001) que repercutem diretamente na composição dos fluidos orgânicos (VALADÃO et al., 1996), modificando-os na dependência do tempo, localização e gravidade do processo de obstrução (NAPPERT \& JOHNSON, 2001).

Em consequência a processos inflamatórios decorrentes de injúria, trauma ou infecção de um tecido, há síntese e liberação das proteínas de fase aguda (PFA), que surgem precocemente na circulação

IDepartamento de Clínica e Cirurgia Veterinária (DCCV), Faculdade de Ciências Agrárias e Veterinárias (FCAV), Universidade Estadual Paulista (UNESP), Jaboticabal, SP, Brasil. E-mail: dessafsn@yahoo.com.br. *Autor para correspondência.

"Laboratório de Clínica e Cirurgia Animal (LCCA), Centro de Ciências e Tecnologias Agropecuárias (CCTA), Universidade Estadual do Norte Fluminense Darcy Ribeiro (UENF), Campos dos Goytacazes, RJ, Brasil.

IIIDepartamento de Ciências Exatas (DCE), Faculdade de Ciências Agrárias e Veterinárias (FCAV), Universidade Estadual Paulista (UNESP), Jaboticabal, SP, Brasil. 
sanguínea. Suas concentrações séricas relacionamse à severidade da afecção e à extensão das lesões teciduais. $\mathrm{Na}$ espécie equina, a Amiloide A sérica (SAA) é considerada a PFA mais sensível, mudando suas concentrações séricas rapidamente perante um dano tecidual ou inflamação aguda (CYWINSKA et al., 2010). Dessa forma, suas qualiquantificações podem prover informações diagnósticas e prognósticas importantes, se mensuradas em tempo ideal (MURATA et al., 2004). A eletroforese de proteínas de fase aguda auxilia no diagnóstico precoce de processos inflamatórios (DI FILIPPO et al., 2010), fornecendo informações sobre elevações ou diminuições nas concentrações de tais proteínas de fase aguda (THOMAS, 2000). Assim, objetivouse avaliar e comparar as concentrações séricas e peritoneais das proteínas de fase aguda em equinos submetidos à obstrução experimental do duodeno, íleo e/ou cólon maior.

\section{MATERIAL E MÉTODOS}

Utilizaram-se vinte e um equinos adultos, sem raça definida, divididos em quatro grupos. Uma semana antes do experimento, foi realizado exame clínico, hemograma e vermifugação, com intuito de garantir que os animais apresentavam-se saudáveis. Três grupos de seis animais tiveram um segmento intestinal diferente obstruído: duodeno (GD), íleo (GI) ou cólon maior (GM), e três animais compuseram o grupo controle (GC), e foram submetidos aos mesmos procedimentos anestésicos e cirúrgicos realizados para os animais dos demais grupos, porém, sem a realização da obstrução de um segmento intestinal.

Com os animais em estação, foi realizada sedação com acepromazina 1\% (Acepran - 0,025mg $\mathrm{kg}^{-1}, \mathrm{IV}$ ) , cloridrato de xilazina $2 \%$ (Virbaxil - 0,5mg $\left.\mathrm{kg}^{-1}, \mathrm{IV}\right)^{\mathrm{b}}$ e meperidina (Dolosal - $4 \mathrm{mg} \mathrm{kg}^{-1}, \mathrm{IM}$ ) ${ }^{\mathrm{c}}$. Ato contínuo, procedeu-se à anestesia local infiltrativa, utilizando-se da associação (1:1) de lidocaína 2\% (Lidovet) $^{\mathrm{d}}$ e de bupivacaína $0,75 \%$ (Neocaína) ${ }^{\mathrm{e}}$, ambas sem vasoconstritor. Conduziu-se então, por meio da laparotomia, flanco direito para duodeno e íleo, e esquerdo para cólon maior, a obstrução do segmento intestinal, com dreno de Penrose $\mathrm{n}^{\mathrm{o}}$ 3, segundo modelo descrito por Datt \& Usenik (1975). Nesse exato momento, os animais receberam cloridrato de tramadol (Tramal - 1,5mg kg-1, IV) f $^{\mathrm{f}}$ As obstruções foram mantidas por três horas e então removidas, permanecendo assim por mais três horas. No pósoperatório, instituiu-se terapia antimicrobiana a base de penicilina benzatina (Pentabiótico Veterinário Reforçado - 30.000UI $\mathrm{kg}^{-1}$, IM) $)^{\mathrm{g}}$ a cada 48 horas, perfazendo três aplicações. Como analgésico e antiinflamatório, administrou-se flunixin meglumine (Flunexina Injetável - 0,5mg $\left.\mathrm{kg}^{-1}, \mathrm{IV}\right)^{\mathrm{h}}$ a cada 24 horas, durante dois dias. As feridas cirúrgicas foram tratadas com polivinilpirrolidona-iodo tópica a $1 \%$, duas vezes ao dia, até a retirada dos pontos no $10^{\circ}$ dia pós-operatório.

As amostras de soro foram colhidas por punção da veia jugular e as de líquido peritoneal foram colhidas por paracentese abdominal nos períodos précirúrgico (T0), três horas após a obstrução (T3), três horas após a desobstrução (T6) e no 1ํㅜ 4ํe 7ํㅡㅁas do pós-operatório (T30, T102 e T174).

As concentrações de proteínas totais foram obtidas pelo método do Biureto, com o auxílio de um conjunto de reagentes ${ }^{i}$ e leituras espectrofotométricas ${ }^{j}$.

Para o fracionamento das proteínas, procedeu-se à eletroforese em gel de poliacrilamida, contendo dodecil sulfato de sódio (SDS-PAGE). Os pesos moleculares e as concentrações das frações proteicas foram determinados por densitometria computadorizadak ${ }^{\mathrm{k}}$. Para o cálculo do peso molecular, foram utilizados marcadores ${ }^{1}$ de pesos moleculares de $200,116,97,66,55,45,36,29,24$ e $20 \mathrm{kDa}$, além das proteínas purificadas ${ }^{1}$ albumina, $\alpha_{1}$-antitripsina, haptoglobina, ceruloplasmina, transferrina $\mathrm{e}$ imunoglobulina $\mathrm{G}$ (IgG).

A análise estatística dos dados foi estabelecida por meio do teste de Tukey, fixando-se a variância em $\mathrm{P}<0,05$ para comparação das médias, através do programa estatístico SAS.

\section{RESULTADOS E DISCUSSÃO}

Nos proteinogramas sérico e do líquido peritoneal, verificaram-se a presença de 20 a 63 frações proteicas, cujos pesos moleculares variaram de 15 a $318 \mathrm{kDa}$. Destas, destacam-se importantes PFA: imunoglobulina A com peso molecular igual a $175 \mathrm{kDa}$, ceruloplasmina $110 \mathrm{kDa}$, transferrina $80 \mathrm{kDa}$, albumina $65 \mathrm{kDa}$, imunoglobulina $\mathrm{G}$ (cadeia pesada com $55 \mathrm{kDa}$ e cadeia leve com $29 \mathrm{kDa}$ ), haptoglobina $42 \mathrm{kDa}, \alpha_{1}$-glicoproteína ácida $39 \mathrm{kDa}$ e uma proteína considerada como de fase aguda, com peso molecular correspondente a $24 \mathrm{kDa}$ (P24) e não identificada nominalmente na literatura. Essa técnica não permite a qualiquantificação da proteína SAA, que, segundo ECKERSALL (2000), para a espécie equina, é avaliada através da técnica de ELISA, utilizando-se substrato quimioluminescente, de difícil mensuração, o que torna o método menos popularizado.

As concentrações das proteínas séricas totais encontradas nos animais (Tabela 1) 
Tabela 1 - Médias e desvios-padrão dos teores séricos de proteína total, transferrina, albumina, ceruloplasmina e haptoglobina de equinos do grupo controle (GC), obstrução de duodeno (GD), obstrução de íleo (GI) e obstrução de cólon maior (GM).

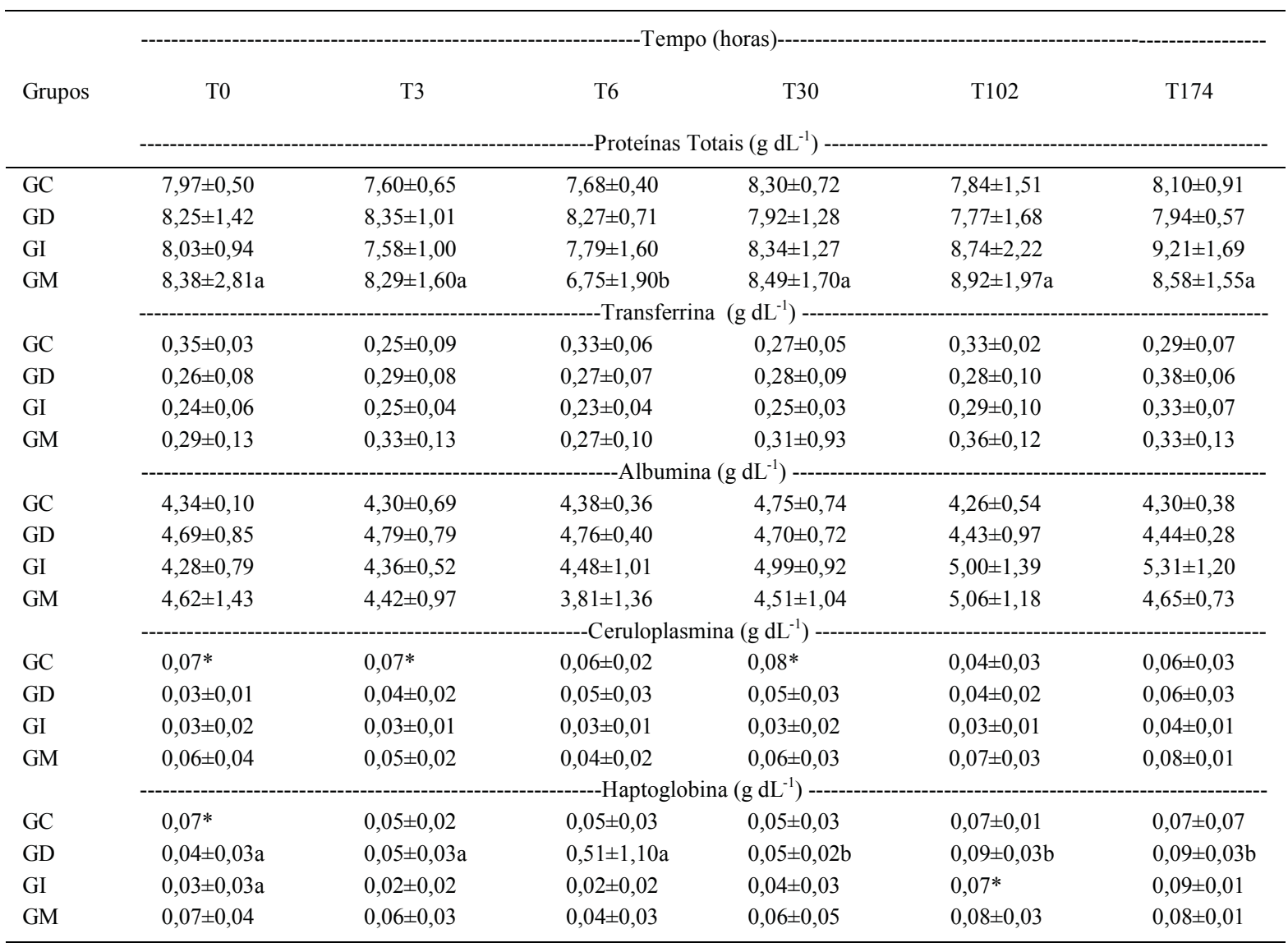

T0: pré-operatório; T3: obstrução; T6: desobstrução; T30-T174: pós-operatório.

Letras maiúsculas distintas indicam diferença significativa entre grupos pelo Teste Tukey $(\mathrm{P}<0,05)$.

Letras minúsculas distintas indicam diferença significativa entre tempos pelo Teste Tukey $(\mathrm{P}<0,05)$.

*Desvio-padrão com valor abaixo da quarta casa decimal menor que zero.

assemelharam-se aos valores de referência para espécie, descritos na literatura (KRAMER, 2000), no intervalo de $5,8-8,7 \mathrm{~g} \mathrm{dL}^{-1}$. No líquido peritoneal, as concentrações elevaram-se significativamente ao longo do período experimental (Tabela 2). Esse aumento, se analisado isoladamente, poderia indicar comprometimento da integridade da parede intestinal, o que acarretaria alteração vascular e consequente extravasamento de fluidos e de elementos plasmáticos para o interior da alça intestinal e/ou cavidade peritoneal, como explicaram VALADÃO et al. (1996). Porém, quando analisado em conjunto com as concentrações obtidas para as proteínas séricas totais, conclui-se que ocorreu resposta inflamatória estimulada pelo ato cirúrgico e pela própria lesão entérica (THOMASSIAN, 1996; LOPES et al., 1999; FAGLIARI \& SILVA, 2002).

À análise do eletroforetograma sérico e peritoneal, constatou-se aumento nos valores das $\alpha$-globulinas ( $\alpha_{1}$-glicoproteína ácida, ceruloplasmina e haptoglobina) no decorrer do tempo (Tabelas 1, 2, 3 e 4). De acordo com MURATA et al (2004), a concentração de haptoglobina aumenta em processos inflamatórios agudos, estresse, procedimentos cirúrgicos, processos inflamatórios experimentais, bem como a ceruloplasmina aumenta significativamente após processos inflamatórios, infecciosos, virais e parasitários (JACOBSEN, 2007). Por sua vez, $\alpha_{1}$-glicoproteína ácida é capaz de auxiliar na remoção de lipopolissacarídeos (LPS) da circulação através da ligação direta com o LPS e, assim, neutralizar sua toxicidade, como explicaram MOORE et al. (1997). Tal assertiva adquire grande relevância quando se avaliam equinos com cólica, visto que os distúrbios gastrintestinais favorecem a transferência de bactérias e toxinas do lúmen intestinal para a corrente sanguínea, contribuindo para 
o desencadeamento do choque séptico. DI FILIPPO et al, 2011, também encontraram concentrações elevadas de $\alpha_{1}$-glicoproteína ácida e haptoglobina em cavalos naturalmente obstruídos, mas não de ceruloplasmina.

Ademais, pode-se inferir que a proteína de peso molecular $24 \mathrm{kDa}$ (P24), encontrada no traçado eletroforético do sangue e do líquido peritoneal, comportou-se como uma PFA positiva, classificada na fração $\alpha_{2}$-globulina; isso porque os valores das concentrações peritoneais dessa proteína aumentaram progressivamente durante toda a fase experimental, alcançando picos de concentração entre o primeiro e o quinto dia pós-operatório (Tabelas 3 e 4), sendo condizente com o comportamento das $\alpha_{2}$-globulinas, descrito por MURATA et al. (2004).

As concentrações séricas de transferrina e albumina variaram ao longo do período experimental
(Tabela 1). De acordo com MURATA et al. (2004), a resposta de fase aguda inclui alterações na concentração das PFA. Algumas delas diminuem sua concentração (PFA negativas), tais como a albumina e a $\beta$-globulina transferrina, enquanto outras aumentam (PFA positivas). O mecanismo pelo qual as PFA negativas diminuem sua concentração não está definido, mas esse processo pode ser rápido, com redução significativa após 24 horas, ou mais gradual, decrescendo ao longo de dias (ECKERSALL, 2008), sendo mais notável em doenças inflamatórias crônicas (ECKERSALL, 2006). Porém, a transferrina e albumina apresentaram elevações nas suas concentrações, no líquido peritoneal, ao longo do tempo (Tabela 2). Essas elevações observadas nas concentrações peritoneais de albumina, de acordo com THOMASSIAN (1996), LOPES et al. (1999) e FAGLIARI \& SILVA (2002), revelam que ocorreu

Tabela 2 - Médias e desvios-padrão dos teores de proteína total, transferrina, albumina, ceruloplasmina e haptoglobina no líquido peritoneal de equinos do grupo controle (GC), obstrução de duodeno (GD), obstrução de íleo (GI) e obstrução de cólon maior (GM).

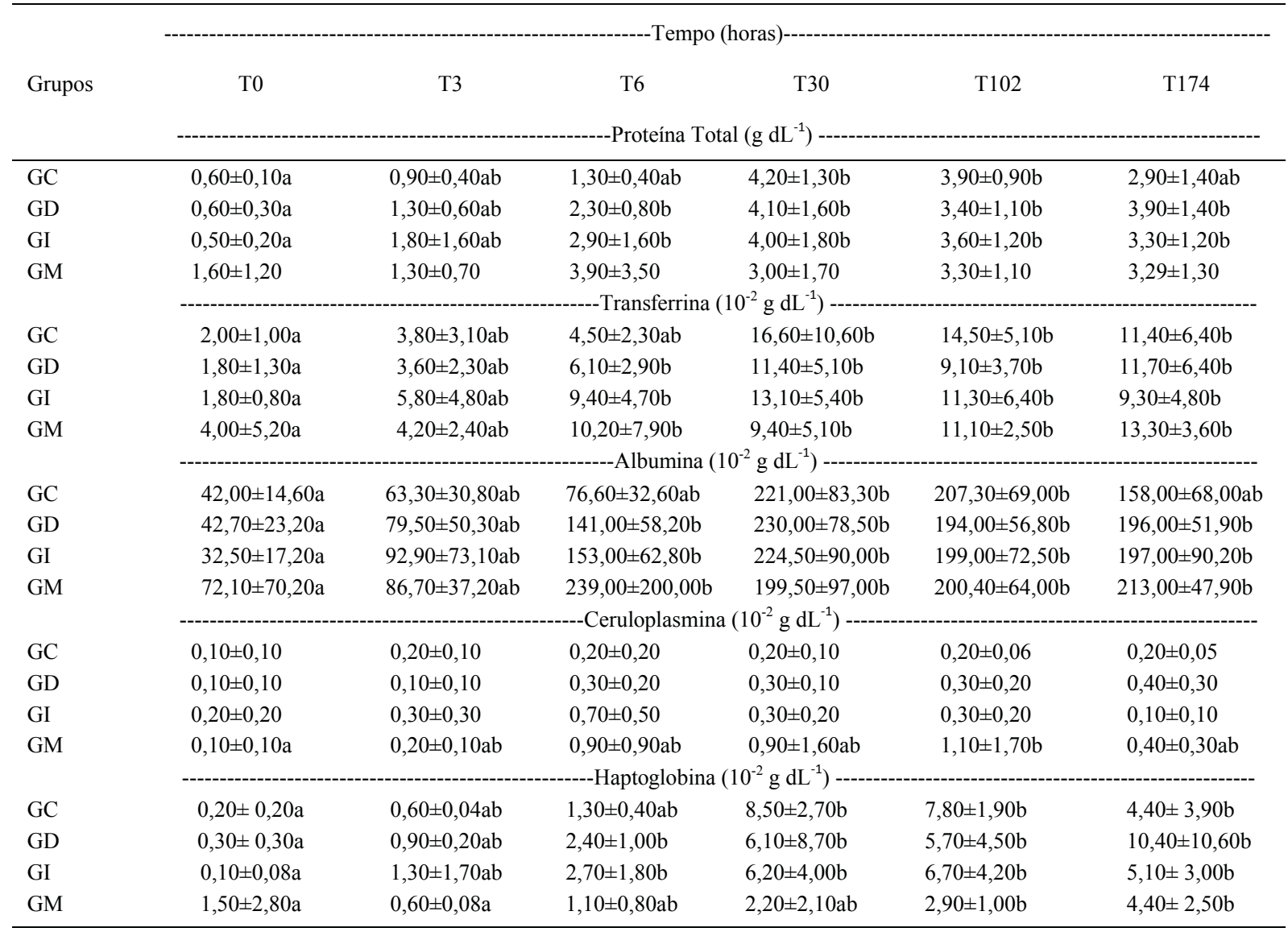

T0: pré-operatório; T3: obstrução; T6: desobstrução; T30-T174: pós-operatório.

Letras maiúsculas distintas indicam diferença significativa entre grupos pelo Teste Tukey $(\mathrm{P}<0,05)$.

Letras minúsculas distintas indicam diferença significativa entre tempos pelo Teste Tukey $(\mathrm{P}<0,05)$. 
Tabela 3 - Médias e desvios-padrão dos teores séricos de ${ }_{1}$-glicoproteína ácida, P24, IgA, IgG-CP e IgG-CL de equinos do grupo controle (GC), obstrução de duodeno (GD), obstrução de íleo (GI) e obstrução de cólon maior (GM).

\begin{tabular}{|c|c|c|c|c|c|c|}
\hline Grupos & T0 & T3 & T6 & T30 & $\mathrm{T} 102$ & $\mathrm{~T} 174$ \\
\hline $\mathrm{GC}$ & $0,01 *$ & $0,01 *$ & $0,01 \pm 0,01$ & $0,01 \pm 0,01$ & $0,01 *$ & $0,02 *$ \\
\hline GD & $0,009 *$ & $0,009^{*}$ & $0,01 *$ & $0,01 *$ & $0,02 \pm 0,02$ & $0,02 \pm 0,02$ \\
\hline GI & $0,009 *$ & $0,008^{*}$ & $0,008^{*}$ & $0,01 *$ & $0,01 *$ & $0,01 *$ \\
\hline GM & $0,01 *$ & $0,01 *$ & $0,01 *$ & $0,02 \pm 0,03$ & $0,01 *$ & $0,02 *$ \\
\hline $\mathrm{GC}$ & $0,22 \pm 0,03$ & $0,22 \pm 0,05$ & $0,23 \pm 0,07$ & $0,27 \pm 0,05$ & $0,23 \pm 0,15$ & $0,29 \pm 0,06$ \\
\hline GD & $0,22 \pm 0,06$ & $0,21 \pm 0,14$ & $0,23 \pm 0,07$ & $0,23 \pm 0,08$ & $0,25 \pm 0,10$ & $0,25 \pm 0,05$ \\
\hline GI & $0,28 \pm 0,16$ & $0,29 \pm 0,13$ & $0,29 \pm 0,08$ & $0,28 \pm 0,08$ & $0,30 \pm 0,11$ & $0,31 \pm 0,07$ \\
\hline GM & $0,16 \pm 0,05$ & $0,21 \pm 0,09$ & $0,26 \pm 0,13$ & $0,31 \pm 0,06$ & $0,28 \pm 0,03$ & $0,27 \pm 0,08$ \\
\hline $\mathrm{GC}$ & $0,15 \pm 0,01$ & $0,17 \pm 0,03$ & $0,20 \pm 0,03$ & $0,16 \pm 0,01$ & $0,20 \pm 0,04$ & $0,24 \pm 0,02$ \\
\hline GD & $0,21 \pm 0,09$ & $0,21 \pm 0,03$ & $0,20 \pm 0,04$ & $0,18 \pm 0,03$ & $0,21 \pm 0,04$ & $0,21 \pm 0,04$ \\
\hline GI & $0,18 \pm 0,04$ & $0,16 \pm 0,03$ & $0,16 \pm 0,03$ & $0,16 \pm 0,02$ & $0,21 \pm 0,04$ & $0,23 \pm 0,02$ \\
\hline GM & $0,16 \pm 0,11 \mathrm{a}$ & $0,22 \pm 0,06 \mathrm{ab}$ & $0,16 \pm 0,04 \mathrm{ab}$ & $0,22 \pm 0,06 \mathrm{ab}$ & $0,26 \pm 0,05 b$ & $0,24 \pm 0,06 \mathrm{~b}$ \\
\hline $\mathrm{GC}$ & $2,96 \pm 0,46$ & $2,05 \pm 0,38$ & $1,98 \pm 0,43$ & $2,15 \pm 0,25$ & $2,32 \pm 0,80$ & $2,57 \pm 0,52$ \\
\hline GD & $2,37 \pm 0,57$ & $2,28 \pm 0,42$ & $2,22 \pm 0,45$ & $2,01 \pm 0,61$ & $1,98 \pm 0,77$ & $1,94 \pm 0,44$ \\
\hline GI & $2,43 \pm 0,52$ & $1,96 \pm 0,58$ & $2,14 \pm 0,64$ & $2,05 \pm 0,60$ & $2,25 \pm 0,72$ & $2,40 \pm 0,52$ \\
\hline GM & $2,15 \pm 1,10$ & $2,45 \pm 0,76$ & $1,68 \pm 0,45$ & $2,38 \pm 0,70$ & $2,30 \pm 0,71$ & $2,28 \pm 0,64$ \\
\hline
\end{tabular}

T0: pré-operatório; T3: obstrução; T6: desobstrução; T30-T174: pós-operatório.

Letras maiúsculas distintas indicam diferença significativa entre grupos pelo Teste Tukey $(\mathrm{P}<0,05)$.

Letras minúsculas distintas indicam diferença significativa entre tempos pelo Teste Tukey $(\mathrm{P}<0,05)$.

*Desvio-padrão com valor abaixo da quarta casa decimal menor que zero.

resposta inflamatória estimulada pelo ato cirúrgico e pela própria lesão entérica.

Para as concentrações de gamaglobulinas IgA e IgG, foram observadas oscilações, tanto no soro como no líquido peritoneal, ao longo do tempo experimentado (Tabelas 3 e 4). Segundo ECKERSALL (2008), o aumento das concentrações de gamaglobulinas pode estar relacionado ao aumento da produção de IL-6 e de outras interleucinas, o que pode causar ativação policlonal inespecífica das células $\mathrm{B}$, resultando na produção de anticorpos de origens diferentes. Ademais, as proteínas da fração $\gamma$, nos animais domésticos, incluem, principalmente, imunoglobulinas IgA, IgM, IgG e IgE sintetizadas pelo sistema imunológico em resposta a estímulos antigênicos e virais (THOMAS, 2000; ECKERSALL, 2008).

As diferenças entre os resultados obtidos nos proteinogramas sérico e peritoneal, muito provavelmente deveram-se à síntese extrahepática das proteínas de fase aguda a partir de tipos celulares heterogêneos de órgãos ou tecidos, incluindo leucócitos (FOURNIER et al., 2000) e, especialmente, por células endoteliais e epiteliais de órgãos que se comunicam com o meio externo, tais como glândula mamária, sistema respiratório e trato gastrintestinal. Segundo JACOBSEN (2007), a determinação das concentrações locais das PFA, por fornecer informações sobre o estado inflamatório/infeccioso de um órgão de particular interesse, aumenta a precisão na instituição do diagnóstico.

\section{CONCLUSÃO}

Oaumento nas concentrações peritoneais de proteína total, $\alpha_{1}$-glicoproteína ácida, ceruloplasmina, haptoglobina, P24, transferrina, albumina, IgA e IgG mostram que o proteinograma do líquido peritoneal, em equinos com cólica, é mais sensível e eficaz no diagnóstico de processos inflamatórios abdominais do que o proteinograma sérico. Esse aumento também pode auxiliar na identificação do estado inflamatório, diagnóstico e na elaboração do prognóstico de equinos com cólica. 
Tabela 4 - Médias e desvios-padrão dos teores de $\alpha_{1}$-glicoproteína ácida, P24, IgA, IgG-CP e IgG-CL no líquido peritoneal de equinos do grupo controle (GC), obstrução de duodeno (GD), obstrução de íleo (GI) e obstrução de cólon maior (GM).

\begin{tabular}{|c|c|c|c|c|c|c|}
\hline Grupos & T0 & $\mathrm{T} 3$ & T6 & $\mathrm{T} 30$ & T102 & $\mathrm{T} 174$ \\
\hline $\mathrm{GC}$ & $0,07 \pm 0,01 \mathrm{a}$ & $0,10 \pm 0,10 \mathrm{ab}$ & $0,10 \pm 0,10 \mathrm{ab}$ & $0,30 \pm 0,20 \mathrm{ab}$ & $1,60 \pm 1,40 \mathrm{~b}$ & $0,70 \pm 0,50 \mathrm{~b}$ \\
\hline GD & $0,05 \pm 0,04 \mathrm{a}$ & $0,20 \pm 0,10 \mathrm{ab}$ & $0,20 \pm 0,10 \mathrm{ab}$ & $0,30 \pm 0,10 \mathrm{ab}$ & $0,50 \pm 0,30 \mathrm{~b}$ & $1,20 \pm 1,00 b$ \\
\hline GI & $0,10 \pm 0,08 \mathrm{a}$ & $0,20 \pm 0,30 \mathrm{ab}$ & $0,30 \pm 0,30 \mathrm{ab}$ & $0,60 \pm 0,30 \mathrm{~b}$ & $0,90 \pm 0,60 \mathrm{~b}$ & $0,50 \pm 0,50 \mathrm{~b}$ \\
\hline GM & \multicolumn{6}{|c|}{ 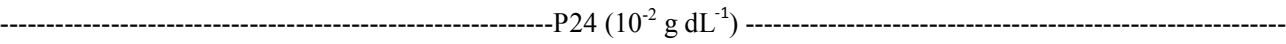 } \\
\hline $\mathrm{GC}$ & $0,90 \pm 0,30$ & $1,40 \pm 1,30$ & $2,10 \pm 1,20$ & $9,10 \pm 7,10$ & $5,50 \pm 3,80$ & $5,50 \pm 3,10$ \\
\hline GD & $1,30 \pm 1,50 \mathrm{a}$ & $2,30 \pm 1,60 \mathrm{ab}$ & $4,10 \pm 1,40 \mathrm{ab}$ & $8,20 \pm 3,20 b$ & $6,70 \pm 4,00 \mathrm{~b}$ & $6,60 \pm 3,90 b$ \\
\hline GI & $0,90 \pm 0,50 \mathrm{a}$ & $4,90 \pm 4,90 \mathrm{ab}$ & $9,80 \pm 7,20 b$ & $12,50 \pm 5,60 \mathrm{~b}$ & $9,40 \pm 3,40 \mathrm{~b}$ & $7,90 \pm 3,10 b$ \\
\hline GM & $3,80 \pm 3,70$ & $3,00 \pm 2.10$ & $9,60 \pm 8,20$ & $6,90 \pm 4,40$ & $10,20 \pm 6,70$ & $9,00 \pm 6,40$ \\
\hline & \multicolumn{6}{|c|}{ - } \\
\hline $\mathrm{GC}$ & $0,30 \pm 0,10 \mathrm{a}$ & $0,90 \pm 0,40 \mathrm{ab}$ & $1,90 \pm 1,40 \mathrm{ab}$ & $7,50 \pm 4,20 \mathrm{~b}$ & $6,70 \pm 3,30 \mathrm{~b}$ & $5,90 \pm 2,80 b$ \\
\hline GD & $0,80 \pm 0,70 \mathrm{a}$ & $2,30 \pm 1,60 \mathrm{ab}$ & $4,10 \pm 1,40 \mathrm{~b}$ & $9,10 \pm 4,30 \mathrm{~b}$ & $8,50 \pm 4,60 \mathrm{~b}$ & $9,00 \pm 3,40 \mathrm{~b}$ \\
\hline GI & $0,30 \pm 0,20 \mathrm{a}$ & $3,10 \pm 3,70 b$ & $6,50 \pm 5,20 \mathrm{~b}$ & $7,50 \pm 4,10 \mathrm{~b}$ & $7,80 \pm 4,90 \mathrm{~b}$ & $5,50 \pm 2,60 b$ \\
\hline GM & $1,60 \pm 2,70 \mathrm{a}$ & $2,30 \pm 1,60 \mathrm{ab}$ & $4,80 \pm 4,00 \mathrm{~b}$ & $4,00 \pm 1,60 \mathrm{~b}$ & $7,40 \pm 2,60 \mathrm{~b}$ & $7,30 \pm 1,80 \mathrm{~b}$ \\
\hline & \multicolumn{6}{|c|}{ - } \\
\hline GC & $9,90 \pm 2,40 \mathrm{a}$ & $15,15 \pm 10,40 \mathrm{ab}$ & $25,10 \pm 6,20 \mathrm{ab}$ & $110,70 \pm 44,00 \mathrm{~b}$ & $103,60 \pm 28,80 \mathrm{~b}$ & $83,00 \pm 42,30 \mathrm{~b}$ \\
\hline GD & $13,30 \pm 6,10 \mathrm{a}$ & $30,90 \pm 14,00 \mathrm{ab}$ & $54,40 \pm 21,40 \mathrm{~b}$ & $110,00 \pm 67,80 \mathrm{~b}$ & $86,40 \pm 35,50 b$ & $104,10 \pm 53,30 \mathrm{~b}$ \\
\hline GI & $10,10 \pm 7,20 \mathrm{a}$ & $55,70 \pm 65,70 \mathrm{ab}$ & $89,30 \pm 68,60 b$ & $106,30 \pm 64,60 \mathrm{~b}$ & $99,80 \pm 38,80 \mathrm{~b}$ & $87,70 \pm 41,20 \mathrm{~b}$ \\
\hline GM & $26,60 \pm 29,30 \mathrm{a}$ & $31,60 \pm 19,60 \mathrm{ab}$ & $98,50 \pm 125,90 \mathrm{ab}$ & $72,30 \pm 39,90 b$ & $86,60 \pm 26,70 b$ & $94,40 \pm 34,90 \mathrm{~b}$ \\
\hline
\end{tabular}

T0: pré-operatório; T3: obstrução; T6: desobstrução; T30-T174: pós-operatório.

Letras maiúsculas distintas indicam diferença significativa entre grupos pelo Teste Tukey $(\mathrm{P}<0,05)$.

Letras minúsculas distintas indicam diferença significativa entre tempos pelo Teste Tukey $(\mathrm{P}<0,05)$.

\section{FONTES DE AQUISIÇÃO}

a - Acepran 1\% ( Univet S.A.)

b - Virbaxil 2\% ( Virbac)

c - Dolosal (Cristália)

d - Lidovet ( Bravet)

e- Neocaína $0,75 \%$ ( Cristália)

f - Tramal (Cristália)

g - Pentabiótico Veterinário Reforçado ( Fort Dodge)

h - Flunixina Injetável (UCB S.A)

i - Labtest (Sistema de Diagnósticos Ltda. - Lagoa Santa, Brasil)

j - Labquest (CELM, modelo E-225-D)

$\mathrm{k}$ - Fotodyne, (Fotodyne Inc, Houston, TX, USA)

1 - Marcador (Sigma Marker 6.500 - 200.000)

\section{COMITÊ DE ÉTICA E BIOSSEGURANÇA}

Comissão de Ética no Uso de Animais (CEUA), da Universidade Estadual Paulista (UNESP), conforme protocolo $\mathrm{n}^{\mathrm{o}}$ 023232-05.

\section{REFERÊNCIAS}

CYWINSKA, A. et al. Serum amyloid A level as a potential indicator of the status of endurance horses. Equine Veterinary Journal, Malden, v.42, Suppl.38, p.23-27, 2010. Disponível em: <http:// onlinelibrary.wiley.com/doi/10.1111/j.2042-3306.2010.00280.x/ pdf>. Acesso em: 05 ago. 2011.
DATT, S.C.; USENIK, E.A. Intestinal obstruction in the horse. Physical signs and blood chemistry. Cornell Veterinarian, Ithaca, v.65, n.2, p.152-172, 1975. Disponível em: <http://www.ncbi.nlm. nih.gov/pubmed/236147\#>. Acesso em: 25 jan. 2009.

DI FILIPPO, P.A. et al. Perfil eletroforético das proteínas séricas e do líquido peritoneal de equinos submetidos à obstrução experimental de duodeno, íleo e cólon maior. Ciência Animal Brasileira, Goiânia, v.11, p.938-946, 2010. Disponível em: <http:// www.revistas.ufg.br/index.php/vet/article/viewFile/9699/8373>. Acesso em: 03 mar. 2011. doi: 10.5216/cab.v11i4.9699.

DI FILIPPO, P.A. et al. Determinação de haptoglobina, ceruloplasmina, $\alpha_{1}$-glicoproteína ácida, transferrina e $\alpha_{1}$ antitripsina, em equinos com cólica. Ciência Rural, Santa Maria, v.41, n.12, p.2108-2113, 2011. Disponível em: <http://www. scielo.br/pdf/cr/v41n12/a20511cr4928.pdf>. Acesso em: 30 maio, 2012. doi: 0103-8478.

ECKERSALL, P.D. Proteins, proteomics, and the dysproteinemias. In: KANEKO, J.J. et al. Clinical biochemistry of domestic animals. Burlington: Academic, 2008. Cap.5, p.117-156.

ECKERSALL, P.D. Acute phase proteins: form, function and analysis. In: ANNUAL MEETING OF THE AMERICAN COLLEGE OF VETERINARY PATHOLOGISTS AND AMERICAN SOCIETY FOR VETERINARY CLINICAL PATHOlOGY, 2006, Tucson, Arizona. Proceedings... Tucson: Hilton Tucson El Conquistador Golf \& Tennis Resort, 2006. V.1, 
p.2-6. Disponível em: <http://vet.sagepub.com/content/43/5/805. full.pdf + html $>$. Acesso em: 11 jan. 2009.

ECKERSALL, P.D. Recent advances and future prospects for the use of acute phase proteins as markers of disease in animals. Revue de Medicine Vétérinaire, Toulouse, v.51, n.7, p.577584, 2000. Disponível em: <http://www.revmedvet.com/2000/ RMV151_577_584.pdf>. Acesso em: 02 dez. 2012.

FAGLIARI, J.J.; SILVA, S.L. Hemograma e proteinograma plasmático de equinos hígidos e de equinos acometidos por abdômen agudo, antes e após laparotomia. Arquivo Brasileiro de Medicina Veterinária e Zootecnia, Belo Horizonte, v.54, n.6, p.559-567, 2002. Disponível em: <http://www.scielo.br/scielo. php?script $=$ sci_arttext\&pid=S010209352002000600001\&lng= pt\&nrm=iso\&tlng=pt>. Acesso em: 03 mar. 2011. doi: <http:// dx.doi.org/10.1590/S0102-09352002000600001>.

FOURNIER T. et al. Alpha-1-acid glycoprotein. Biochimica et Biophysica Acta, Philadelphia, n.1482, p.157-171, 2000. Disponível em: <http:/www.ncbi.nlm.nih.gov/pubmed/11058758>. Acesso em: 03 mar. 2011. doi: 11058758.

JACOBSEN, S. Review of equine acute-phase proteins. In: ANNUAL CONVENTION OF THE AMERICAN ASSOCIATION OF EQUINE PRACTITIONERS, 53., 2007, Orlando, Flórida. Proceedings... Orlando: University of Florida, 2007. V.53, p.230-235

KRAMER, J.W. Normal hematology of the horse. In: FELDMAN, B.F. et al. Schalm's veterinary hematology. Canadá: Lippincott Williams e Wilkins, 2000. Cap.4, p.1069-1074.

LARANJEIRA, P.V.E.H.; ALMEIDA, F.Q. Síndrome cólica em equinos: ocorrência e fatores de risco. Revista de Ciências da Vida, Rio de Janeiro, v.28, n.1, p.64-78, 2008. Disponível em: $<$ http://www.editora.ufrrj.br/rcv2/vida\%2028-1/64-78.pdf $>$. Acesso em: 04 mar. 2011. doi: 0104-7264.

LOPES, M.A.F. et al. Exame do fluido peritoneal e hemograma de equinos submetidos à laparotomia e infusão intraperitoneal de carboximetilcelulose. Ciência Rural, Santa Maria, v.29, n.1, p.79 85, 1999. Disponível em: <http://www.scielo.br/pdf/cr/v29n1/ a15v29n1.pdf>. Acesso em: 03 mar. 2011. doi: 0103-8478.

MOORE, D.F. etal. Alpha-1-acid(AAG, orosomucoid) glycoprotein: Interaction with bacterial lipopolysaccharide and protection from sepsis. Inflammation, v.21, n.1, p.69-82, 1997. Disponível em: $<$ http://www.springerlink.com/content/n434g558788x3672>. Acesso em: 03 mar. 2011. doi: 10.1023/A:1027342909423.

MURATA, H. et al. Current research on acute phase proteins in veterinary diagnosis: an overview. Veterinary Journal, Londres, v.168, n.1, p.28-40, 2004. Disponível em: <www.elsevier.com/ locate/tvjl>. Acesso em: 03 mar. 2011. doi:10.1016/S10900233(03)00119-9.

NAPPERT, G.; JOHNSON, P. Determination of the acid-base status in 50 horses admitted with colic between December 1998 and May 1999. Canadian Veterinary Journal, Ottawa, v.42, n.9, p.703-707, 2001. Disponível em: <http://www.ncbi.nlm.nih.gov/ pmc/articles/PMC1476611/pdf/canvetj00009-0037.pdf>. Acesso em: 04 mar. 2011. doi: PMC1476611.

NEVES, M.M. et al. Valores referenciais da análise do líquido peritoneal de equinos sadios. Ciência Rural, Santa Maria, v.30, n.5, p.809-811, 2000. Disponível em: <http://www.scielo.br/pdf/ cr/v30n5/a11v30n5.pdf>. Acesso em: 15 fev. 2010. doi: 01038478 .

THOMAS, J.S. Overview of plasma proteins. In: FELDMAN B.F. et al. Schalm's veterinary hematology. Canadá: Lippincott Williams e Wilkins, 2000. Cap.8, p.891-898.

THOMASSIAN, A. Enfermidade dos cavalos. São Paulo: Varela, 1996. 3v.

TRAUB-DARGATZ, J.L. A estimate of the national incidence of and operation level risk factors for colic among horses in the United States, spring 1998 to spring 1999. Journal of the American Veterinary Medical Association, Schaumburg, v.219, n.1, p.67-71, 2001. Disponível em: <http://avmajournals.avma. org/doi/pdf/10.2460/javma.2001.219.67>. Acesso em: 03 mar. 2011. doi: 0003-1488.

VALADÃO, C.A.A. et al. Aspectos bioquímicos do plasma e fluido peritoneal de equinos com cólica. Brazilian Journal Veterinary Research Animal Science, São Paulo, v.33, n.1, p.32-35, 1996. Disponível em: <http://bases.bireme.br/cgi-bin/wxislind.exe/iah/ online/?IsisScript $=\mathrm{iah} / \mathrm{iah} . \mathrm{xis} \& \mathrm{src}=$ google $\&$ base $=$ LILACS\&lan $\mathrm{g}=\mathrm{p} \&$ nextAction $=$ lnk\&exprSearch $=257066 \&$ indexSearch $=$ ID $>$. Acesso em: 04 mar. 2011. doi: 257066 